\title{
POLICY Policy and pregnancy: the impact on working families in the NHS
}

\author{
Authors: Nada Al-Hadithy, ${ }^{A}$ Rebecca Nicholas, ${ }^{B}$ Katie Knight, ${ }^{C}$ Rose Penfold, ${ }^{D}$ Greta McLachlan ${ }^{\mathrm{E}}$ and Lucia Magee
}

The NHS is the largest employer in the UK, with $77 \%$ of its workforce made up by women. The UK Health and Safety Executive clearly states that 'risks to a pregnant woman and her baby must be minimised by employers'. Recent studies demonstrate that shift work, uncontrolled working hours and night shifts increase risks to the developing fetus; however, this evidence has not been taken up by the NHS. Our analysis explores women's experience of conception and pregnancy in the NHS.

The thematic analysis from the survey results identified several key areas: feeling unable to speak up to their trainers and programme directors; unable to control their work patterns; conflicting and inconsistent guidance; and being caught between occupational health and the trust or deaneries. This subsequently leads to greater stress, longer unnecessary exposure to occupational hazards, and complications in pregnancy and career outcomes.

KEYWORDS: policy, pregnancy, gender, discrimination

DOI: $10.7861 /$ fhj.2020-0259

\section{Introduction}

The NHS employs 1.5 million people, of whom $77 \%$ are women. ${ }^{1}$ The UK Health and Safety Executive clearly states that 'risks to a pregnant woman and her baby must be minimised by employers'. Our study attempts to identify the difficulties pregnant women face while working in the NHS. It is a qualitative study to explore women's experience of conception and pregnancy in the NHS.

Authors: A plastic surgery trainee, Oxford University Hospitals NHS Foundation Trust, Oxford, UK; B plastic surgery trainee, Great Ormond Street Hospital for Children NHS Foundation Trust,

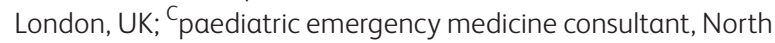
Middlesex University Hospital NHS Trust, London, UK; D academic clinical fellow, Guy's and St Thomas' NHS Foundation Trust, London, UK; E' 'higher surgical trainee, Kent, Surrey, and Sussex Deanery, and leadership fellow, Cleveland Clinic London Hospital, London, UK; F academic clinical fellow, St George's University Hospitals NHS Foundation Trust, London, UK
Through qualitative research methodologies, we hoped to identify the key themes that present barriers.

There is ample evidence that the clinical workforce experiences more difficulties conceiving and during pregnancy than the nonclinical workforce. A recent meta-analysis has provided proof that working nightshifts while pregnant leads to a $21 \%$ increased risk of preterm delivery and a $23 \%$ increased risk of pregnancy loss. ${ }^{3}$ Pregnant women working more than 40 hours per week are $38 \%$ more likely to experience a pregnancy loss and $21 \%$ more likely to deliver preterm. ${ }^{4,5}$ Rogers et al found that pregnant female trainee surgeons were more likely to have adverse pregnancy events compared with the partners of male trainee surgeons $(65.0 \%$ vs $11.5 \% ; p=0.0002$ ) or than with female non-surgical colleagues $(p=0.0329){ }^{6}$

There have been many reports of clinical staff who request to come off on-calls, nights or to reduce their working hours only to be told that there is 'no evidence' that working long hours harms them or their babies. They are made to feel they are not a 'team player' and eventually get told 'no' or are penalised. ${ }^{7}$ However, the untoward events that result from these management decisions are not captured or aggregated and the data is not transparent. Indeed, there is no national requirement for all NHS trusts to do exit interviews for those leaving the NHS. This has been piloted in Solent NHS Trust. ${ }^{8}$

There is significant variation in pregnancy policy and risk assessments within the NHS. Some London foundation trusts' policy is to stop on-calls for all pregnant psychiatry doctors as soon as they inform their employer, whereas many other trusts will ask doctors to stay on the on-call rota until 30 weeks. Some risk assessments do not specifically comment on established hazards to pregnant women, such as anaesthetic gases, radiation, teratogenic chemicals or iodine. ${ }^{9}$ Similar problems are faced by nurses and other members of the clinical workforce; theatre scrub nurse: 'I was not told about all the risks of chemicals I am in contact with. Only found out from this post. Long shifts and heavy lists despite being on light duties due to previous miscarriages.'

The regulation of working lives for pregnant women in the NHS is dependent on vague guidance from NHS Employers which does not quote the most up-to-date evidence and perpetuates inaccuracies that, in some trusts, are used to prevent women from protecting themselves and their unborn children while working in the NHS. ${ }^{10}$ This makes navigating the system confusing, difficult and, ultimately, is detrimental to the progress of women in healthcare. It also impacts the national ambition to halve the rates of stillbirths by 2030 , through the NHS Saving babies' lives initiative. ${ }^{11}$ 
The objective of our study was to capture and explore women's experience of conception and pregnancy in the NHS.

\section{Methods}

We used qualitative research methodology in order to better understand the complex issues women and men with families face while navigating training and working in the NHS. A survey was developed by the authors following discussion with women and men who worked in the NHS in different roles, levels and grades and experienced difficulties while pregnant or trying to navigate maternity or paternity leave. The survey was then piloted with 10 people for usability and interpretability. There were amendments made on this basis and it was subsequently disseminated via social networks (Twitter and Facebook), WhatsApp groups and email networks of women and men working in the NHS.

These data have not been previously captured and, therefore, the study was designed to capture all possible staff-reported experiences through an easily accessible online survey with open questions and wide inclusion criteria. The authors hoped to collect data from across the UK.

The inclusion criteria were women or men who had been pregnant or on maternity or paternity leave while working in the NHS in all parts of the UK. Male allies were also encouraged to complete the survey. Participants were purposively selected or self-selected, and further participants were captured through snowballing technique. It was disseminated from 10 August 2019 to 10 November 2019

The survey is available from supplementary material S1.

All data was stored on an encrypted computer and anonymised. A thematic analysis of survey responses was conducted using Braun and Clarke's 6-step framework (Box 1). ${ }^{12}$

\section{Results}

The analysis was conducted by an author trained in qualitative research methodology. The data collection was a document study where the survey responses were reviewed by the researcher. ${ }^{13}$ The documents were coded, sorted, grouped, summarised and catergorised. $^{14}$

One-hundred and seventy people completed the survey; 10 were men and 160 were women. Of the 160 women who completed the survey, 126 women had experienced pregnancies while working in the NHS. These 126 women commented on 183 pregnancies between them. Fifty-six the respondents were Black, Asian and minority ethnic (BAME) and all had experienced difficulties in pregnancy. The specialties of these 126 women are summarised in Table 1.

Box 1. Braun and Clarke's six-phase framework for doing a thematic analysis

Step 1: Become familiar with the data

Step 2: Generate initial codes

Step 3: Search for themes

Step 4: Review themes

Step 5: Define themes

Step 6: Write up
Table 1. Specialties

Occupational health

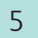

Physiotherapy

Pharmacy

Dentistry

Midwifery

Nursing

General practice

Accident and emergency

Psychiatry

Clinical oncology

Anaesthetics

Surgery

Medical

Paediatrics

Thirteen women reported no problems with their working conditions during their 13 pregnancies. Some of the reports of good practice can be seen supplementary material $\mathbf{S}$.

One-hundred and thirteen women experienced difficulties over 170 pregnancies; 56 of these women were BAME. There was wide variation in when respondents came off their on-call duties, ranging from 13 weeks to 33 weeks. The earliest untoward workplace event took place in 1999 but the majority occurred in the last 3 years. These problems occurred across the country and included Cheshire, Cumbria, Derbyshire, Devon, Dorset, Durham, Essex, Gloucestershire, Greater Manchester, Herefordshire, Lancashire, London, Northumberland, Nottinghamshire, Oxfordshire, Scotland, Staffordshire, Suffolk, Yorkshire and others.

The thematic analysis of difficulties experienced is summarised in Table 2. Many women experienced multiple occupational hazards with unsafe work conditions.

Several women commented that, although they could stop nights and on-calls, they had to make up for it by doing more oncalls earlier in their pregnancy or with long days and working more shifts over the course of the week resulting in longer total working hours. Many had their hours reduced but then lost their pay and this impacted their maternity pay.

These untoward working environments while pregnant and working for the NHS were associated with various negative health and pregnancy outcomes (Table 3).

The respondents perceived that their pregnancies and associated complications led to certain negative career outcomes (Table 3).

\section{Discussion}

In her bestselling book, Invisible Women, Caroline Criado Perez highlights that women are disadvantaged in their access to healthcare. ${ }^{15}$ This includes delayed endometriosis diagnosis, adverse pregnancy outcomes during pandemics and how women's healthcare services are often in acute and in continual demand. $^{16-19}$

From our survey, it is apparent that women working in the NHS are also at increased risk of poor outcomes to their health and the health of their fetuses. It is well established that radiation 
Table 2. Thematic analysis of difficulties

experienced during pregnancy

Inconsistent guidance

Poor risk assessment

Advised to speak to occupational health to reduce hours / 137

on-call pattern but occupational health requested a

referral and not able to help without long delays

Loss of autonomy / involvement in discussion regarding working patterns

Unable to reduce working hours / come off on-call rota

Unable to take adequate breaks

No rest facilities

Felt pressure to do unsafe things

Bullying and harassment

Placed at a hospital with a long commute

Unsafe workplace conditions:

Exposure to potentially violent patients (GP/psychiatry

home visits)

Exposure to radiation

Exposure to non-scavenged anaesthetic gases

Exposure to infection risk (chicken pox or CMV)

Exposure to chemicals

Lack of support (solely on call)

Forced to do transfers of patients

Lack of support for return to work 48

$\mathrm{CMV}=$ cytomegalovirus; $\mathrm{GP}=$ general practice.

decreases the chances of implantation and is harmful to the fetus, especially in the first 8 weeks. ${ }^{20}$ However, of 183 pregnancies, 35 were exposed to radiation. Two fetuses had anomalies and, although it is difficult to confirm causality, it is not best practice regardless. The current literature states that exposure of $1 \mathrm{mSv}$ over the course of a pregnancy is safe. ${ }^{21}$ However, this is crude with little reflection on the fact that organogenesis occurs in weeks $0-8$ and, if the entire $1 \mathrm{mSv}$ is received during this period, it may lead to pregnancy loss or deformity. In addition, dosiometers are not widely available nor mentioned in risk assessments. One trainee was asked to wear lead to allegedly protect her fetus from technetium-99 from sentinel lymph node biopsies. However, gamma radiation is not stopped by lead. ${ }^{22-24}$

Twenty-six pregnancy losses occurred in 183 pregnancies $(14.2 \%)$, which is greater than the national average of $12 \% .{ }^{25}$

It is also well established that exposure to anaesthetic gases leads to increased risk of spontaneous pregnancy loss with a relative risk of 1.9 of spontaneous abortion (pre-scavenging). ${ }^{26,27}$ Yet, 20 pregnancies were exposed to anaesthetic gases in which the clinician felt to be unsafe.

Many clinical staff were told that they could not alter their working patterns and had to start maternity leave early. This is in direct contradiction to the government guidance that only within the last 4 weeks of pregnancy are pregnancy-related health problems a cause to start maternity leave early.

Women did not feel able to speak up to their trainers and programme directors, were not able to control their work patterns, had conflicting and inconsistent guidance, and felt

\section{Table 3. Negative outcomes}

\section{Negative health and pregnancy outcomes}

Health complications

Bleeding in pregnancy while on call 17

Braxton Hicks while on call $\quad 6$

Repeated collapse $\quad 12$

Pelvic girdle pain $\quad 8$

Sciatica 15

Recurrent infections in the mother 8

Pregnancy loss in the first trimester $\quad 11$

Pregnancy loss in the second/third trimester 15

Pre-term delivery 9

Intrauterine growth restriction 15

Fetal anomaly 4

Uterine rupture 2

Bleed behind placenta 2

Near death in the mother 2

Difficulty conceiving 8

Delayed starting family and fertility problems $\quad 7$

\section{Negative career outcomes}

Negative impact on career $\quad 48$

Held back / failed annual review of competency 12

progression

Loss of salary (forced to start maternity leave early / 13

missed on-call deducted)

Gave up training number but stayed in specialty 10

Left specialty $\quad 5$

Left NHS 6

Middle grade contract not extended 2

Some responses are seen in supplementary material S3.

caught between occupational health and the trust or deaneries. This subsequently led to greater stress, and longer unnecessary exposure to occupational hazards and complications. Some of these have been devastating and others have made clinical staff leave the NHS entirely.

The government has laid out very clear guidance for employers regarding occupational hazards in pregnancy. ${ }^{2}$

If the risk cannot be removed employers must take the following actions.

> Action 1: Temporarily adjust her working conditions and/or hours of work. If that is not possible, then proceed to action 2.

> Action 2: Offer her suitable alternative work (at the same rate of pay), if available. If that is not possible, then proceed to action 3.

$>$ Action 3: Suspend her from work on paid leave for as long as necessary to protect her health and safety and that of her child.

However, within the NHS there is huge unwarranted variation in fulfilling these requirements from the poor risk assessment, unclear pathway to action, and pressure and bullying to continue unsafe practice. The way that pregnant patient-facing clinical staff are treated results in negative financial and career progression outcomes. A recent survey of surgical trainees demonstrated that $>27 \%$ of pregnant doctors did not feel supported by their department during pregnancy. ${ }^{28}$ Liang et al identified 'lack of pathways for independent and specific support' as one of the key reasons that women leave clinical careers. ${ }^{29}$

Although the data were collected before the pandemic, during this write up, the unwarranted variation throughout the NHS has 
never before been so lethal. During the COVID-19 pandemic, many patient-facing pregnant clinical workers have been told to continue working despite being in the 'high-risk' governmental category and should be self-isolating. The intersectionality of gender and race is brought into stark relief during this time. ${ }^{30}$ Heightened focus on risk assessments for BAME staff is currently an urgent issue in view of the greater number of deaths in this community in the NHS during the COVID-19 pandemic. ${ }^{31}$ Recent reports from MBBRACE and the BMJ special issue, Racism in medicine, have identified women from BAME communities are more likely to die while pregnant. $^{32,33}$

This is by no means a comprehensive analysis, subject to selfselection bias. Further work is required. Given that qualitative research is characterised by responsivity to context, the steps of data collection and analysis were iterative. If further research is carried out, the data collected from that work would lead to a deeper understanding of the study questions and will lead to adaption and expansion of the original plan. ${ }^{34}$

An analysis should be done by NHS England of every trust and NHS facility in the country for their risk assessment pro forma and policy on pregnancy for patient-facing clinical staff. With women making up $77 \%$ of the NHS workforce, pressure to address the gender pay gap and bring more women into board membership, an urgent overhaul of policy related to pregnancy is required.

It is clear that NHS Employers must issue more detailed information on what risk assessments should include based on the most up-to-date clinical trials. Greater transparency is required with specific national standards to mandate all pregnant women across all NHS establishments are given the option to:

$>$ come off the on-call rota when the patient-facing clinical staff requests without a general practitioner or occupational health letter, or consultant approval

$>$ work less than 40 hours, if required

$>$ stop doing tasks that require wearing heavy protective clothing

$>$ stop working with radiation from conception

$>$ stop working with non-scavenged anaesthetic gases

$>$ have access to information on common occupational hazards (such as iodine-based scrub solutions, cytotoxic drugs, heavy lifting, infection risks, cement, chemicals or radiation) and how to avoid them.

Trusts must be held to account with data disaggregated for gender, race and other protected characteristics, and reported, collated and presented in an open and transparent fashion.

The Supported Return to Training programme will address some of the issues regarding returning to work following time out. ${ }^{35}$

We understand that some women will choose to balance training opportunities with raising a family and adjustments can be made to allow this, but the ability to protect her unborn child from harm must ultimately be supported as we cannot expect the individual to overcome an institution on her own.

\section{Supplementary material}

Additional supplementary material may be found in the online version of this article at www.rcpjournals.org/fhj:

S1 - Survey questions.

S2 - Reports of good practice.

S3 - Responses regarding outcomes.

\section{Conflicts of interest}

Nada Al-Hadithy, Katie Knight, Rose Penfold, Greta McLachlan and Lucia Magee are all co-founders of Women Speakers in Healthcare (www.womenspeakersinhealthcare.co.uk), an organisation set up to improve gender balance at all healthcare events.

\section{References}

1 Sealy R. Women on boards: 50:50 by 2020. NHS, 2017.

2 Health and Safety Executive. Protecting new and expectant mothers at work. HSE. https://www.hse.gov.uk/mothers/employer/ index.htm

3 Kolte AM, Bernardi LA, Christiansen OB, Quenby S et al. Terminology for pregnancy loss prior to viability: a consensus statement from the ESHRE early pregnancy special interest group. Hum Reprod 2015;30:495-8.

4 Cai C, Vandermeer B, Khurana R et al. The impact of occupational shift work and working hours during pregnancy on health outcomes: a systematic review and meta-analysis. Am J Obstet Gynecol 2019;221:563-76.

5 Puentes Morales EV. Rapid Response: Re: Working during pregnancy: five minutes with ... Margie Davenport. BMJ 2019;366:15061. www.bmj.com/content/366/bmj.I5061/rr

6 Mohan H, Ali O, Gokani V] et al. Surgical trainees' experience of pregnancy, maternity and paternity leave: a cross-sectional study. Postgrad Med J 2019;95:552-7.

7 Campbell D. Dossier reveals 'petty tortures' of NHS trainee doctors denied leave. The Guardian, 2019. www.theguardian.com/ society/2019/mar/28/nhs-trainee-doctors-denied-leave-dossierhospitals [Accessed 02 March 2021].

8 NHS Shared Business Services. Solent NHS Trust: Reducing employee turnover through enhanced exit interview process. NHS. www.sbs.nhs.uk/case-studies-exit-interview-service

9 South Warwickshire Clinical Commissioning Group. Maternity, Paternity, Adoption and Parental Leave Policy. South Warwickshire CCG, 2016. www.southwarwickshireccg.nhs.uk/ mf.ashx?ID=9de4ce3a-af87-49a1-a5c4-9e888713d781 [Accessed 02 March 2021].

10 Royal College of Physicians. Physical and shift work in pregnancy: Occupational aspects of management. RCP, 2009.

11 NHS England. Saving Babies' Lives: A care bundle for reducing stillbirth. NHS, 2016. www.england.nhs.uk/wp-content/uploads/2016/03/ saving-babies-lives-car-bundl.pdf [Accessed 02 March 2021].

12 Braun V, Clarke V. Using thematic analysis in psychology. Qualitative Research in Psychology 2006:3:77-101.

13 Russell CK, Gregory DM. Evaluation of qualitative research studies. Evidence Based Nursing 2003;6:36-40.

14 Shenton AK. Strategies for ensuring trustworthiness in qualitative research projects. Education for Information 2004;22:63-75.

15 Caroline Criado Perez. Invisible Women: Exposing Data Bias in a World Designed for Men. Penguin, 2020.

16 Surrey E, Soliman AM, Trenz H, Blauer-Peterson C, Sluis A. Impact of endometriosis diagnostic delays on healthcare resource utilization and costs. Adv Ther 2020;37:1087-99.

17 Brolin Ribacke KJ, van Duinen AJ, Nordenstedt $\mathrm{H}$ et al. The impact of the West Africa Ebola outbreak on obstetric health care in Sierra Leone. PLOS ONE 2016:11:e0150080.

18 Kanem N. Women, girls, health workers must not be overlooked in global COVID-19 response. United Nations Population Fund, 2020 www.unfpa.org/press/women-girls-health-workers-must-not-beoverlooked-global-covid-19-response?page $=18$

19 Rimmer MP, Al Wattar BH, on behalf of the UKARCOG Members. Provision of obstetrics and gynaecology services during the 
COVID-19 pandemic: a survey of junior doctors in the UK National Health Service. BJOG 2020;127:1123-8.

20 Centers for Disease Control and Prevention. Radiation and Pregnancy: A Fact Sheet for Clinicians. CDC, 2019. www.cdc.gov/ nceh/radiation/emergencies/prenatalphysician.htm?CDC_AA_ refVal=https \% 3A \% 2F \% 2Femergency.cdc.gov \% 2Fradiation \% 2F prenatalphysician.asp [Accessed 03 July 2020].

21 Health and Safety Executive. Working safely with ionising radiation: Guidelines for expectant or breastfeeding mothers. HSE, 2015. www.hse.gov.uk/pUbns/indg334.pdf [Accessed 02 March 2021].

22 Eskandar OS, Eckford SD, Watkinson T. Safety of diagnostic imaging in pregnancy. Part 1:X-ray, nuclear medicine investigations, computed tomography and contrast media. The Obstetrician \& Gynaecologist 2010;12:71-8.

23 National Radiological Protection Board, College of Radiographers, Royal College of Radiologists. Diagnostic Medical Exposures: Advice on exposure to ionising radiation during pregnancy. National Radiological Protection Board, 1998.

24 The British Institute of Radiology. Guidance on using shielding on patients for diagnostic radiology applications. BIR, 2020. www.bir. org.uk/media/414334/final_patient_shielding_guidance.pdf

25 Royal College of Physicians, Faculty of Occupational Medicine. Advising women with a healthy, uncomplicated, singleton preg nancy on: shift work and the risk of miscarriage and preterm delivery. NHS Health at Work. www.nhshealthatwork.co.uk/images/ library/files/Clinical\% 20excellence/Pregnancy_info_shiftwork_ A4.pdf [Accessed 03 July 2020].

26 Boivin JF. Risk of spontaneous abortion in women occupationally exposed to anaesthetic gases: a meta-analysis. Occup Environ Med 1997;54:541-8.

27 Centers for Disease Control and Prevention. Reproductive health and the workplace: Anesthetic Gases. CDC, 2019. www.cdc.gov/ niosh/topics/repro/anestheticgases.html
28 Mohan H, Ali O, Gokani V et al. Surgical trainees' experience of pregnancy, maternity and paternity leave: a cross-sectional study. Postgraduate Medical Journal 2019;95:552-7.

29 Liang R, Dornan T, Nestel D. Why do women leave surgical training? A qualitative and feminist study. Lancet 2019;393:541-9.

30 Crenshaw K. Demarginalizing the intersection of race and sex: A black feminist critique of antidiscrimination doctrine, feminist theory and antiracist politics. University of Chicago Legal Forum 1989;1989:139-167.

31 Public Health England. Disparities in the risk and outcomes of COVID-19. PHE, 2020. https://assets.publishing.service.gov.uk/ government/uploads/system/uploads/attachment_data/ file/908434/Disparities_in_the_risk_and_outcomes_of_COVID_ August_2020_update.pdf [Accessed 02 March 2021].

32 MBRRACE-UK. MBRRACE-UK: Perinatal Mortality Surveillance Report: UK Perinatal Deaths for Births from January to December 2018. MBRRACE-UK, 2020. www.npeu.ox.ac.uk/assets/downloads/ mbrrace-uk/reports/perinatal-surveillance-report-2018/ MBRRACE-UK_Perinatal_Surveillance_Report_2018_-_final_v3.pdf

33 Anakwe L. Ethnic disparities in maternal care. BMJ 2020;368:m442.

34 Fossey E, Harvey C, McDermott F, Davidson L. Understanding and evaluating qualitative research. Aust N Z J Psychiatry 2002;36: 717-32.

35 Health Education England. Supported Return to Training: SuppoRTT. Health Education England. www.hee.nhs.uk/our-work/ supporting-doctors-returning-training-after-time-out [Accessed 27 November 2020].

Address for correspondence: Dr Nada Al-Hadithy, Radcliffe Hospital, Headley Way, Oxford OX3 9DU, UK.

Email:nadaucl@yahoo.com

Twitter: @HadithyNada 